\title{
MULHERES IDOSAS VÍTIMAS DE VIOLÊNCIA: O PROTAGONISMO NAS DENÚNCIAS
}

\author{
Daniela Garcia Damaceno*, Miriam Fernanda Sanches Alarcon** \\ Viviane Boacnin Yoneda Sponchiado***, Mara Quaglio Chirelli****, \\ Maria José Sanches Marin*****, Joyce Fernanda Soares Albino Ghezzi
}

\section{Resumo}

A fim de compreender a vivência de mulheres idosas vítimas de violência intrafamiliar na denúncia e os sentimentos que a permeiam, o estudo foi realizado a partir de entrevistas com idosas que realizaram denúncia em uma delegacia de um município de São Paulo. O processamento dos dados deu-se pela análise temática. Foi observado que a denúncia representa a retomada do protagonismo, sendo marcada pela dualidade entre o empoderamento e os sentimentos em relação ao agressor. Percebe-se que a denúncia de maus tratos para essa população é marcada por contradições entre a interrupção da violência e a relação com o agressor, mostrando-se essencial o estímulo do protagonismo a partir de estratégias de empoderamento em suas diferentes dimensões.

Palavras-chave: Empoderamento, envelhecimento, violência contra a mulher, violência intrafamiliar.

* Universidade do Oeste Paulista e Faculdade de Medicina de Botucatu da Universidade Estadual Paulista «Júlio de Mesquita», Botucatu, São Paulo, Brasil.

Endereço postal: Av. Prof. Mário Rubens Guimarães Montenegro, s/n - UNESP - Campus de Botucatu - Botucatu/SP - CEP 18618687, Brasil.

Endereço eletrônico: daniela.garciasw@gmail.com

ORCID: http://orcid.org/0000-0001-8656-009X

** Faculdade de Medicina de Botucatu da Universidade Estadual Paulista «Júlio de Mesquita», Botucatu, São Paulo, Brasil.

Endereço eletrônico: miriam@uenp.edu.br;

ORCID: http://orcid.org/0000-0002-2572-9899

*** Delegacia de Defesa da Mulher na Central de Polícia Judiciária da Polícia Civil do Estado de São Paulo, Marilia-SP, Brasil.

Endereço postal: R. Dr. Joaquim de Abreu Sampaio Vidal, 49-Alto Cafezal, Marília-SP, 17506130, Brasil.

Endereço eletrônico: puffy_yoneda@hotmail.com;

ORCID: http://orcid.org/0000-0003-4527-6345

**** Faculdade de Medicina de Marília, Marília, São Paulo, Brasil.

Endereço postal: R. Monte Carmelo, 800 - Fragata, Marília - SP, 17519-030, Brasil.

Endereço eletrônico: marachirelli@gmail.com;

ORCID: https://orcid.org/0000-0002-7417-4439

***** Faculdade de Medicina de Marília, Marília, São Paulo, Brasil.

Endereço eletrônico: marnadia@terra.com.br;

ORCID: http://orcid.org/0000-0001-6210-6941

****** Faculdade de Medicina de Botucatu da Universidade Estadual Paulista «Júlio de Mesquita», Botucatu, São Paulo, Brasil.

Endereço eletrônico: jo.albino1988@gmail.com

ORCID: https: //orcid.org/0000-0002-5808-613X 
Abstract

Older women victims of violence: Their protagonism in reporting it to the Police

In order to understand the experience of older women victims of intrafamily violence when reporting it to the Police and the feelings permeating it, the study was conducted from interviews with older women who reported it at a Police station of a city in the state of São Paulo. Data processing was performed through thematic analysis. It was observed that reporting to the Police represents regaining protagonism, being characterized by the duality between empowerment and the feelings in relation to the aggressor. It is perceived that, for this population, reporting maltreatment to the Police is characterized by contradictions between stopping violence and the relation with the aggressor, being essential to foster protagonism from strategies for empowerment in its different dimensions.

Keywords: Empowerment, aging, violence against women, intrafamily violence.

\section{Resumen}

Mujeres mayores víctimas de violencia: el protagonismo en las denuncias

Para comprender la experiencia de las mujeres mayores víctimas de violencia intrafamiliar en la denuncia y los sentimientos que la permean, el estudio se realizó a partir de entrevistas con mujeres mayores que informaron situaciones de violencia intrafamiliar en una estación de policía en una ciudad de São Paulo. Los datos fueron procesados por análisis temático. Se observó que la denuncia representa la reanudación del protagonismo, estando marcada por la dualidad entre el empoderamiento y los sentimientos hacia el agresor. Se advierte que la denuncia de malos tratos para esta población está marcada por contradicciones entre la interrupción de la violencia y la relación con el agresor, demostrando ser esencial el estímulo del protagonismo desde estrategias de empoderamiento en sus diferentes dimensiones.

Palabras-clave: Empoderamiento, envejecimiento, violencia contra la mujer, violencia intrafamiliar.

\section{Introdução}

Ao longo dos séculos XX e XXI, os movimentos feministas têm contribuído para as conquistas das mulheres em diferentes espaços sociais, acadêmicos e políticos. Contudo, a construção e as assimetrias sociais de género impactam diretamente na liberdade individual e coletiva das mulheres, sendo elas submetidas a uma trajetória imposta pela sociedade e cultura (Beauvoir 2009).

Nesse sentido, encontra-se a violência sobre as mulheres como um denominador comum presente nos diferentes contextos geográficos e sociopolíticos (Ockerent 2011). Enraizado histórica, cultural, econômica e socialmente, caracteriza-se pelo (ab)uso das relações de poder sobre um indivíduo ou coletividade provocando-lhes sofrimentos nas diversas dimensões do sujeito, manifestando-se, assim, de diferentes formas (Leite et al. 2014; Mascarenhas et al. 2016).

Essas manifestações, que se relacionam e se realimentam, somadas aos determinantes sociais, que aumentam a vulnerabilidade das mulheres, e o impacto 
multidimensional da violência a estabelecem como um importante problema de saúde pública (Leite et al. 2014).

Segundo dados do Atlas da Violência (IPEA e FBSP 2019), em 2017, mais de 221 mil mulheres registraram agressão física em decorrência de violência intrafamiliar, número que ainda pode estar subestimado se considerado o grande número daquelas que não denunciam, assim como a indiferença e subnotificação frente aos tipos de violência.

É de ressaltar que nesse mesmo ano, foram mortas 13 mulheres por dia no Brasil. Assim, entre os anos de 2007 e 2017, observou-se um aumento de 30,7\% dos casos de homicídios de mulheres, verificando-se concomitantemente a diminuição das taxas fora da residência $(3,3 \%)$ e o aumento daquelas dentro do domicílio $(17,1 \%)$ (IPEA 2019).

A dimensão sociológica da violência associada à posição de subordinação, à desvalorização e à falta de reconhecimento do papel social das mulheres, ainda que de maneira velada, mostra-se um determinante fundamental para a ocorrência da violência nos diferentes contextos (Macedo 2015). Dessa forma, as relações patriarcais, que atribuem ao sexo masculino o papel de dominação e controle do «outro sexo», facilitam a aceitação de práticas violentas de subjugação (Beauvoir 2009; Duarte et al. 2015).

O fenômeno de bater na mulher (wife beating) - que se refere à aceitação cultural e, algumas vezes, assegurada por leis, da violência contra as mulheres em casos considerados como de insubordinação da mulher mostra-se como um fator de perpetuação da violência de gênero (Aslam, Zaheer e Shafique 2015; Tran, Nguyen e Fisher 2016; Ahinkorah, Dickson e Seidu 2018). A aceitação dessa prática está diretamente associada à cultura de dominação masculina e varia de $2 \%$ a 90,2\% entre os países subdesenvolvidos e em desenvolvimento (Tran, Nguyen e Fisher 2016). Essa aceitação mostra-se mais profunda nas gerações anteriores, em que as relações de poder entre os homens e as mulheres são ainda mais díspares.

Destarte, com o envelhecimento a violência sobre as mulheres toma novas dimensões, uma vez que se associam duas condições: o «ser mulher» e o «ser idosa». Dessa forma, além da representação simbólica das mulheres, os conflitos no âmbito familiar, institucional e convívio social provenientes do estado de fragilidade física ou emocional e da representação social da população acima de 60 anos expõem as mulheres idosas a situações de maior vulnerabilidade à violência (Paraíba e Silva 2015).

Embora grande parte das mulheres idosas apresente um risco elevado a sofrer violência, a subnotificação dos casos mostra-se ainda mais frequente nessa população. Dessa forma, as denúncias, muitas vezes, são realizadas quando estão em causa severos comprometimentos físicos. Nesses casos, essas mulheres, que apresentam fortes laços afetivos com seus agressores, experienciam sentimentos de culpa e vergonha acarretando na negação e justificação do comportamento violento do seu agressor (Souto et al. 2015). 
Frente a um contexto complexo e marcados por vulnerabilidades como apresentado anteriormente, surgem as seguintes questões: Como mulheres idosas vítimas de violência intrafamiliar denunciam os maus-tratos? Quais os sentimentos que permeiam esse processo? Assim, objetiva-se compreender a vivência de mulheres idosas vítimas de violência intrafamiliar na denúncia de maus-tratos e os sentimentos que a permeiam.

\section{Materiais e percurso metodológico}

Trata-se de uma pesquisa qualitativa de campo, realizada no intuito de viabilizar a interpretação do significado da denúncia de maus-tratos para mulheres idosas vítimas de violência intrafamiliar. A presente investigação faz parte de um projeto maior, intitulado «Idoso/a vítima de violência: a interface entre a assistência à saúde, assistência jurídica e assistência social para o desenvolvimento de intervenções» com o subprojeto «O protagonismo das mulheres idosas no combate a violência sobre as mulheres: cidadania, educação e saúde».

A pesquisa foi realizada em Marília, um município de médio porte do centro-oeste paulista, cuja população é de 230154 habitantes, dos quais 17,16\% são pessoas idosas (SEADE 2019). Teve como cenário a Central de Polícia Judiciária da Polícia Civil do Estado de São Paulo do município, mais especificamente a Delegacia de Defesa da Mulher (DDM), que está organizada em dez unidades, distribuídas em cinco distritos policiais, quatro delegacias especializadas que atendem às demandas do município todo (Delegacia de Homicídios, Delegacia de Defesa da Mulher, Delegacia de Investigações Sobre Entorpecentes e Núcleo Especial Criminal) e uma Delegacia da Polícia Civil de Plantão. O município estudado não possui delegacia especializada para o atendimento de pessoas idosas, dessa forma a DDM é responsável pela assistência a essa população.

Foram realizadas 12 entrevistas com mulheres idosas vítimas de violência e atendidas na DDM. Utilizaram-se entrevistas abertas que possibilitaram que as idosas discorressem livremente acerca da vivência do processo de denúncia. As idosas foram indicadas pela delegada responsável mediante a busca delas pelo serviço, assim, a seleção se deu a partir do contato das pesquisadoras com essas mulheres. A coleta de dados foi conduzida por três pesquisadoras experientes em pesquisa qualitativa com título mínimo de mestre.

Os critérios de inclusão foram: ser mulher; ter mais de 60 anos; e ter procurado a DDM. Foram excluídas as participantes cuja denúncia foi realizada por terceiros e que tivessem condições cognitivas que comprometessem a sua participação na pesquisa. Houve um encontro com cada idosa com duração média de uma hora e trinta minutos. As coletas aconteceram de janeiro a novembro de 2018 nas dependências da DDM e, em alguns casos, devido a dificuldades de locomoção das vítimas, nas residências das idosas em dias e horários previamente pactuados. 
Nos casos em que a entrevista foi realizada no domicílio da idosa, o agressor não estava presente. Durante o processo de coleta, apesar de se tratar de um tema complexo, apenas uma idosa recusou participar da investigação. As entrevistas foram gravadas em áudio e transcritas posteriormente.

A amostra foi construída por meio da estratégia da saturação teórica, isto é, os dados foram coletados até que a codificação se revelou saturada. Assim, a coleta ocorreu até que nenhum dado novo ou relevante surgisse em relação a qualquer tema, explorando as propriedades, dimensões e interlocuções do tema (Strauss e Corbin 2008).

Para a análise dos dados obtidos, optou-se pela técnica da Análise Temática proposta por Braun e Clarke (2006). Trata-se de um método analítico qualitativo que busca identificar, analisar e relatar padrões dentro dos dados, buscando a interpretação de diferentes aspectos do tema da investigação. É um método essencialmente independente de um referencial teórico específico, podendo ser aplicado em uma variedade de abordagens teóricas e epistemológicas.

Dessa forma, pela liberdade teórica, fornece uma ferramenta flexível, útil e potente para produzir um conjunto rico e detalhado de dados ainda que complexos. Na presente investigação, utilizou-se a vertente contextual do método que reconhece as formas pelas quais os indivíduos dão significado às suas experiências e como o contexto social interfere nesse processo (Braun e Clarke 2006).

A operacionalização da análise, realizada por duas pesquisadoras experientes com título de mestre, ocorreu em seis fases, de modo não linear, realizado em um movimento de «ir e vir» ao longo das fases. A etapa 1 («familiarizando-se com seus dados») compreendeu a imersão das pesquisadoras nos dados coletados, buscando a aproximação profunda com o conteúdo da pesquisa. Nessa fase foram registradas as principais ideias encontradas nos dados. A etapa 2, representada pela figura 1, teve como produto a realização da codificação inicial, identificando os conteúdos semânticos ou latentes dos dados. Trabalhou-se sistematicamente com o conjunto das informações buscando identificar aspectos interessantes e significativos do texto.

A fase 3, que designamos por «buscando por temas», consistiu na busca de temas, triando inicialmente o produto da codificação, possibilitando a construção da coleção de temas e subtemas, ou seja, focou-se no nível mais amplo constituindo os temas potenciais. Nesta fase, inicia-se a identificação das relações entre os códigos, entre os temas, e entre diferentes níveis de temas (subtemas).

Após a elaboração do mapa temático inicial, na etapa 4, os temas foram revisitados e refinados considerando os critérios de homogeneidade interna e heterogeneidade externa. Nesta fase, os temas foram divididos e apresentavam distinções claras e identificáveis. Dessa forma, ocorreu a recodificação dos dados no intuito de constituir-se um novo mapa temático.

Na sequência, na etapa 5, os temas finais foram definidos e nomeados, identificando-se a essência de cada tema e a existência de subtemas, assim como a 
Figura 1.

Árvore de códigos iniciais, etapa 2 do processo de análise.

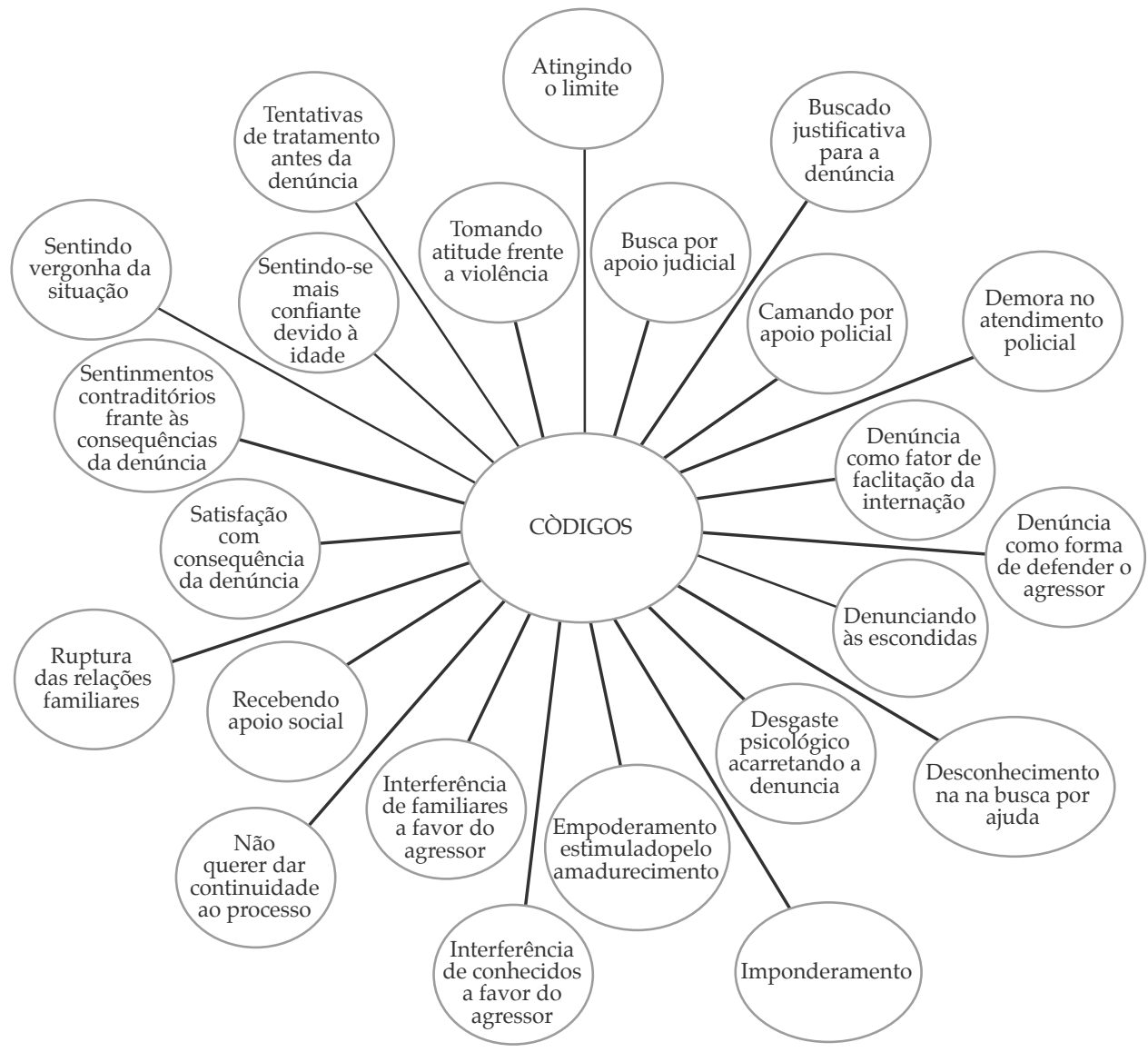

hierarquia de sentidos presente nos dados, determinando quais os aspectos dos dados que cada tema capturava.

A fase final da análise, fase 6, iniciou-se com a produção do relatório de análise que conta a história completa dos dados, com o propósito de indicar ao/à leitor/a o mérito e a validade da análise, incorporando os fragmentos das falas das participantes à narrativa analítica e ilustrando todo o conteúdo a ser mostrado (Braun e Clarke 2006). Todo o processo de análise foi analisado e validado por uma pesquisadora experiente com título de doutora.

O projeto maior e o subprojeto que deram origem a esta investigação foram aprovados pelo Comitê de Ética em Pesquisa com Seres Humanos da instituição proponente, parecer n..$^{\circ} 2.253 .887$ e n. ${ }^{\circ} 3.250 .756$, respectivamente ligados ao Comitê Nacional de Ética em Pesquisa, atendendo à resolução 510/2015 para pes- 
quisas realizadas com seres humanos. As idosas, que por livre e espontânea vontade participaram da pesquisa, assinaram previamente um Termo de Consentimento Livre e Esclarecido (TCLE). Para a apresentação dos resultados, as idosas foram indicadas pela letra «I», seguida da sequência numérica crescente (I1, I2 ... e I12).

\section{Resultados}

As 12 mulheres idosas entrevistadas apresentavam variação de idade de 60 a 79 anos, com predomínio da faixa etária dos 60 aos 69. A maioria era de cor branca, sem trabalho remunerado, e cristã. Houve predomínio do ensino fundamental e ensino médio incompletos. Essas mulheres contavam com grau de parentesco com os agressores, que residiam com elas, sendo filhos e/ou cônjuges.

O processo de denúncia, para mulheres idosas vítimas de violência intrafamiliar atendidas na DDM, representa uma forma de «tornarem-se as protagonistas» da sua própria vida e, consequentemente, interromperem o ciclo da violência. Entretanto, conforme demonstrado na figura 2, apresenta-se, também, como um fenômeno permeado por sentimentos contraditórios - como empoderamento, tristeza, alívio, culpa - influenciados pelas relações sociais.

\section{Figura 2.}

Mapa temático final, mostrando os dois temas principais. Etapa cinco: definindo e nomeando os temas.
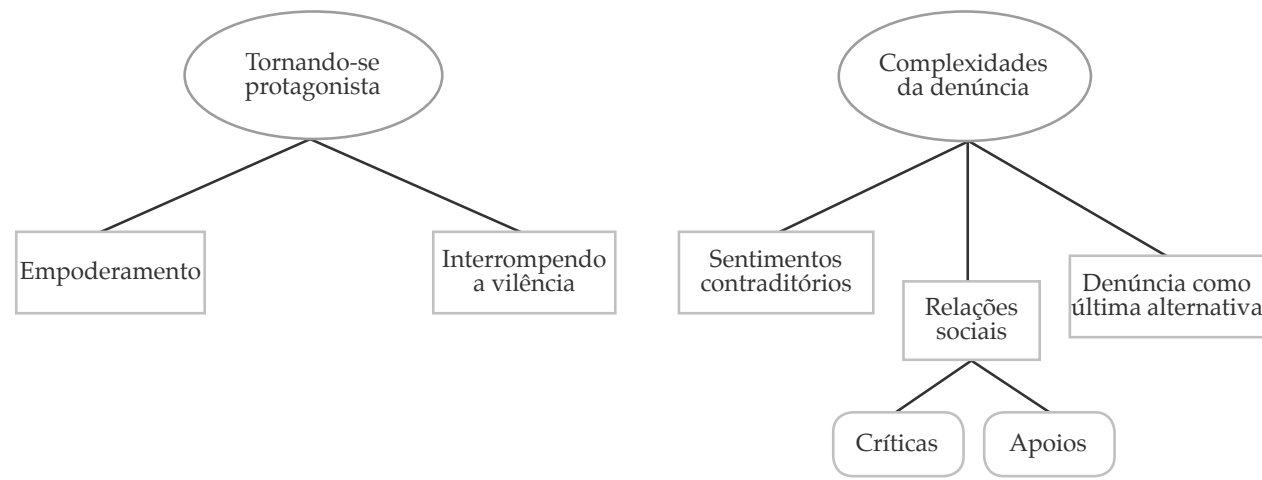

\section{Tornando-se protagonista}

A vivência da denúncia ocasiona nessas mulheres idosas o sentimento de retomada do protagonismo em sua vida, sendo marcada pelos sentimentos de empoderamento e alívio com a interrupção da violência. Assim, ao se sentirem 
capazes de transformar a realidade, muitas vezes vivida por décadas, modificam a autopercepção e autoestima, experienciando o sentimento de vida mais digna.

Empoderamento: Segundo as mulheres entrevistadas, um dos subtemas relacionados ao protagonismo é o sentimento de empoderamento, sentindo-se aptas a se libertarem da situação opressora na qual viviam. Para elas, muitas vezes, este sentimento está relacionado ao amadurecimento promovido pela idade, reconhecendo os seus direitos e modificando a forma de enxergarem o mundo ao seu redor.

Agora, se ele voltar ao que era antes, como uns 12 anos atrás, tudo bem. Se não voltar, eu vou tirar ele da casa. (I4)

Fiz o boletim na polícia e falei que não vou retirar [risos]. A gente tem que ser, a gente tem que ter amor-próprio. Depois do amor a Deus, o amor-próprio, porque, com dignidade, a gente tem que impor respeito para as pessoas. Não é porque é marido ou viveu 40 anos junto que tem direito de fazer certas coisas. I8

Minha vida mudou muito depois que ele saiu de casa. Quando ele estava, eu não tinha paz na minha vida, não tinha paz. Ah! Eu estou no céu, minha filha! Aí, eu sinto paz, que eu posso dormir, posso comer. (I9)

Eu não vou dormir preocupada sobre ameaça de um filho, não tem como! Eu quero fazer as coisas legais. É um direito que eu tenho, pois eu tenho 63 anos e a minha sogra com 82. (I4)

Quando a gente tem 20 anos, a gente tem uma ideia; quando a gente tem 30 a gente pensa diferente; quando a gente tem $40 \ldots$ e, quando você chega nos 60, você já amadureceu em tudo. Fisicamente, emocionalmente, espiritualmente, você tem outra visão de tudo na vida. A gente aprende. Eu falei «Nossa, precisei chegar nos 60 anos, quase 65 para aprender isso!» Ele ficava com as crises dele. Já ficava aqui dentro junto vivendo aquilo. Aí eu falei «Ué, por que que eu estou fazendo isso comigo?» Porque chega uma hora que a gente toma decisões, e durante a vida a gente amadurece. A gente tem os estágios da vida que a gente amadurece em tudo, que as pessoas falam que envelheceu, não é não, é que você amadureceu! E aí você abre os olhos para muitas coisas que, às vezes, a vida toda você enxergou diferente. (I8)

Interrompendo a violência: Para essas mulheres, ao sentirem-se como protagonistas de sua própria história, retomam o poder acerca de suas próprias vidas e fortalecem a capacidade de tomar decisões, possibilitando a interrupção da violência sofrida

Eu não vou ficar vivendo com um pesadelo desse que é o meu filho, [...] então chegou uma hora que eu pensei, ou tomo providência legal ou vai sair morte. (I2)

Eu tinha já feito um BO [boletim de ocorrência], acho que uma vez ou duas dele, só que eu fui lá e retirei, porque a gente pode ir lá e retirar. Falei «ah não!» Eu era mais 
nova, a gente falava, assim «vai mudar», ele prometia, só que agora eu falei assim «não!» É bom deixar lá feito. (I8)

Agora, dessa vez eu falei «Não, chega! Chega, deixa eu viver em paz com esse menino e você já está criado. Vive para lá». (I5)

\section{Complexidade da denúncia}

Contudo, depreendeu-se, também, que o processo de denúncia é complexo e permeado por diferentes dimensões. Assim, essas mulheres vivenciam sentimentos ambivalentes, apoios e críticas de familiares e conhecidos, levando, muitas vezes, a ruptura na dinâmica dessas relações familiares.

Sentimentos contraditórios: As idosas manifestam sentimentos contraditórios ao denunciarem seus agressores, especialmente por estarem envolvidos vínculos afetivos. Nesse sentido, ao mesmo tempo que relatam que estão fartas da violência, preocupam-se com o bem-estar do agressor, atribuindo à adicção ou a transtornos mentais o comportamento violento. Dessa forma, buscam, muitas vezes, justificar a realização da denúncia.

É que aquele dia nós estávamos nervosos, tudo assim nervoso. Então nem correu atrás para ver. E vou falar a verdade, eu não queria que fizesse nada com ele não. (I1)

Eu pedi há um ano e meio a interdição dele. Justamente naqueles dias ele arrumou um emprego e mãe é uma coisa besta. Mãe acha que vai mudar. Então eu peguei, fui lá e retirei o pedido, não deveria ter retirado. (I2)

Ele já agrediu, sim, mas só que o caso dele também não é cadeia, o caso dele é internamento, porque, se for para jogar numa cadeia, [...] eu prefiro que Deus tira ele e que ele morra na rua, porque cadeia não resolve para ele não. (I7)

Ele pirou da cabeça, eu saí e fui com o papel para internar ele, aí quando cheguei minha casa estava toda aberta, que ele quebrou a porta, a fechadura e tudo [...] aí eu chamei a polícia aquele dia. Ele chegou a quebrar minha porta. Eu acho que fiquei brava com isso, que eu fiquei com ele, quebrar minha porta e deixar aberta. (I12)

Relações Sociais: A complexidade relaciona-se, também, com as relações sociais marcadas pelo apoio e críticas de familiares e conhecidos, a ruptura de relacionamento com o agressor e a aceitação da violência em virtude da própria construção social de gênero.

É que nem eu não queria visitar ele. Quarta-feira mesmo, depois de amanhã, é a visita. Eu penso assim, se eu for lá, ele vai falar: «eu faço o que faço para ela e ela vem me ver». Será que não passa isso na cabeça dele? (I3)

Eu só não coloquei ele para fora por causa da irmã dele, ela não aceita. Ela está contra, falou: «mãe, a senhora interna ele, mas prender não, a senhora dá um jeito de inter- 
nar». Eu falei que vou fazer assim: «então eu vou internar e quando ele sair de lá, ele vai procurar o lugar dele, está bom para você?» E falei para a minha filha, que, se fosse na casa dela, ela não ia querer o irmão. (I4)

É uma questão de honra pra mim! Eu tenho meus filhos, tenho meus netos, eles têm que ter uma estrutura em mim. Então eu me seguro, vou levando, mas essas coisas acabam com o emocional da gente, você não vê a pessoa com os mesmos olhos mais, se tinha amor, não tem aquele amor mais, é isso que acontece. (I8)

Achei muita gente para dar força para mim, viu. «Não deixa, assim não porque a senhora está sofrendo», você tem que tomar uma atitude de mãe. (I9)

Denúncia como última alternativa: Entretanto, embora as situações vividas acarretem um profundo sofrimento, algumas vezes a denúncia só é realizada com a finalidade de ajudar o agressor, seja no intuito de facilitar a internação compulsória para tratamento de adicções ou para protegê-lo de pessoas da comunidade.

A vizinhança falou que, se a lei não toma conta, eles vão tomar. Os vizinhos estão ameaçando. Falei para o meu marido para irmos tomar providência. (I4)

Quando eu fiz a ocorrência para o que aconteceu, eu falei para o delegado, eu só queria que ele, não era assim pra prender ele, eu só queria deixá-lo para ficar para lá e eu ficar pra cá. (I5)

Eu fiz o BO dele para ajudar a internar, que isso aí eu fui orientada pela assistente social do Hospital Espírita e pela própria advogada. Se eu não internar, ele vai morrer logo. Ele entra na frente dos carros. Ele entra e os carros é que têm que parar. E se uma hora não dá tempo? (I7)

\section{Discussão}

Nas falas das idosas vítimas de violência, que reportaram a situação por conta própria, identifica-se que a denúncia era permeada por sentimentos ambivalentes, que ora contribuíram, ora dificultaram sua efetivação. Dessa forma, configura-se como um processo complexo que envolve relações familiares envoltas por laços afetivos (Damaceno et al. 2019).

O empoderamento mostrou-se um fenômeno essencial para a realização da denúncia. Trata-se de um processo contínuo e multidimensional no qual as idosas, ao se reconhecerem frente às situações de violência e possuindo as ferramentas necessárias, transformam os contextos sociais e individuais, buscando e movimentando sua rede de apoio e, consequentemente, interrompendo a violência (Batliwala 1997; Cortez e Souza 2008).

Na perspectiva freireana, relaciona-se a capacidade de deter o saber (de si e do mundo) com o empoderamento. Assim, o significado atribuído ao empo- 
deramento é o de libertar-se da situação opressora, revelando-se como um processo gradual e desafiador no qual faz-se necessário o acesso a diferentes recursos (Freire 1997; Chisvert-Terazona e Cambronero-García 2017). Nesse sentido, o investimento no empoderamento feminino visa desestabilizar as redes patriarcais, rompendo com as raízes que perpetuam a violência sobre as mulheres (ChisvertTerazona e Cambronero-García 2017).

Os dados da presente investigação possibilitaram identificar a idade/amadurecimento como um fator de empoderamento dessas mulheres, atribuindo ao mesmo a capacidade para o enfrentamento das situações de opressão (Damaceno et al. 2019). Assim, as conclusões estão na linha de outras pesquisas que mostraram que a idade, a escolaridade e a independência financeira revelam uma relação proporcional positiva à capacidade de as mulheres resistirem e/ou interromperem as situações de abuso (Grose e Grabe 2014).

Identificou-se que - apesar do desgaste ocasionado pelo sofrimento emocional, físico e psíquico nas situações de violência - as mulheres idosas vivenciam sentimentos contraditórios acerca de seus agressores devido aos laços afetivos existentes, comprometendo, muitas vezes, a continuidade do processo judicial. A coexistência de sentimentos e relações dialéticas contribuem para a perpetuação da violência, visto que elas apresentam posturas de negação e omissão das situações, conformando-se como um segundo fator de sofrimento, buscando justificar, seja a terceiros ou a si próprias, a realização da denúncia.

A contradição, contudo, mostra-se como um movimento inerente à humanidade, sendo a transformação dos fenômenos/realidades somente possível a partir da coexistência dessas forças opostas tendendo, concomitantemente, à unidade e à oposição (Gadotti 1990).

Dessa forma, embora expressem sentimentos negativos frente à violência, amam, se compadecem e tentam proteger seus agressores, sentindo-se culpadas por realizarem o boletim de ocorrência, e justificam seus comportamentos agressivos (Souto et al. 2015). Assim, enaltecem as características positivas deles e atribuem seu comportamento a transtornos psiquiátricos, admitindo como aceitável no âmbito familiar situações abusivas, mas buscam a superação da situação de maus-tratos (O'Brien et al. 2011).

A construção do gênero por parte destas mulheres, associado aos papéis sociais de mães, esposas e cuidadoras, provoca a reprodução de comportamentos ensinados por suas mães e avós, impactando diretamente na resolução da situação de violência a partir da denúncia, associando-a, muitas vezes, ao descumprimento desse «papel». Assim, essas idosas comprometem sua saúde física e mental, expondo-se a situações violentas, devido à preocupação com reações de seus familiares e conhecidos (Crockett, Brandl e Dabby 2015).

É valido ressaltar, então, o fator de transferência intergeracional na violência sobre as mulheres. Desse modo, a manutenção da ordem social de gênero e seus papéis sociais, assim como a aceitação da opressão de seus parceiros é transmitida 
como um comportamento aprendido de mães para filhas (Aslam, Zaheer e Shafique 2015; Tran, Nguyen e Fisher 2016; Ahinkorah, Dickson e Seidu 2018).

As conclusões da pesquisa efetuada evidenciam a importância das redes de apoio no enfrentamento da violência. Para as mulheres entrevistadas o apoio de familiares/conhecidos impactou diretamente na realização da denúncia. Assim, observa-se que a constituição dessas redes foi determinante nas respostas das idosas frente ao fenômeno, facilitando o processo de reportar a agressão e diminuindo seu sofrimento psíquico (Souto et al. 2015). Já a falta de apoio perpetua as situações de violência, comprometendo a autoestima dessas mulheres a partir da manutenção de sentimentos de invisibilidade, falta de esperança e impotência (Crockett, Brandl e Dabby 2015).

Desse modo, ao retomarem o papel de protagonistas de suas histórias, essas mulheres deparam-se com obstáculos internos e emocionais provenientes de sua percepção de si enquanto mulheres, e externos, reforçados pelas reações sociais. Ressalta-se, então, que a perpetuação da opressão sobre as mulheres é constituída por cadeias estruturais, institucionalizadas e culturalmente construídas, preservadas e reproduzidas.

Nesse sentido, resgatando a perspectiva freireana e a importância em se romper com as relações tradicionais de subordinação das mulheres, faz-se necessário abordar o empoderamento feminino nos diferentes cenários de formação de homens e mulheres a fim de romper a relação opressor-oprimido que permeia a situação das mulheres no mundo (Freire 1997). Importa, também, desenvolver redes de atenção a mulheres idosas vítimas de violência com enfoque na transformação social e política em todas as idades, conscientizando, dialogando, refletindo criticamente e agindo na coletividade (Riutort e Rupnarain 2017).

\section{Considerações finais}

As mulheres idosas vítimas de violência, que a denunciaram por conta própria, vivenciam o processo como um movimento complexo para a retomada do papel de protagonistas de suas vidas, considerando a idade como um fator que auxilia no enfrentamento do fenômeno. A coexistência de sentimentos e reações sociais contraditórias permeiam todo o processo, mostrando-se, muitas vezes, como fatores de sofrimento, sendo influenciados diretamente pelos papéis sociais de género aprendidos pelas mulheres e associados ao feminino, os quais são construídos sociológica e culturalmente. Faz-se necessário, então, que essas mulheres reconheçam seu papel de protagonistas de suas vidas, buscando transformar suas realidades de opressão, não só a nível individual, como também contribuindo para o empoderamento da coletividade, desenvolvendo estratégias capazes de fomentar esse movimento. Ressalta-se, por fim, que a constituição de políticas públicas voltadas para o empoderamento dessas mulheres deve contribuir para a inserção 
social das mesmas, modificando a representação social de sua condição enquanto «mulheres» e «idosas».

\section{Agradecimentos}

As autoras agradecem o apoio da Coordenação de Aperfeiçoamento Pessoal de Nível Superior (CAPES) no desenvolvimento deste trabalho, por meio da concessão de bolsas de estudo, e da Fundação de Amparo à Pesquisa do Estado de São Paulo (FAPESP) pelo auxílio financeiro.

\section{Referências bibliográficas}

Ahinkorah, Bright Opoku, Kwamena Sekyi Dickson, e Abdul-Aziz Seidu. 2018. «Women decision-making capacity and intimate partner violence among women in sub-Saharan Africa.» Archives of Public Health. DOI: https://doi.org/https://doi.org/10.1186/ s13690-018-0253-9

Aslam, Syeda Kanwal, Sidra Zaheer, e Kashif Shafique. 2015. «Is spousal violence being "vertically transmitted" through victims? Findings from the Pakistan Demographic and Health Survey 2012-13.» PLOS ONE 10 (6): e0129790. DOI: https://doi. org/10.1371/journal.pone.0129790

Batliwala, Srilatha. 1997. «El significado del empoderamiento de las mujeres: nuevos conceptos desde la acción.» In Poder y empoderamiento das mujeres, organizado por Magdalena Léon, 187-211. Santa Fe de Bogotá: TM Editores.

Beauvoir, Simone de. 2009. O segundo sexo. 2. ${ }^{\text {a }}$ ed. Traduzido por Sergio Milliet. Rio de Janeiro: Nova Fronteira.

Braun, Virginia, e Victoria Clarke. 2006. «Using thematic analysis in psychology.» Qualitative Research in Psychology: 77-101. DOI: https://doi.org/10.1191/1478088706qp063oa

Chisvert-Terazona, María José, e Pilar Cambronero-García. 2017. «De la vulnerabilidad al empoderamiento a través de la educación. Una mirada de género desde el lenguaje fílmico.» Em Ecos de Freire e o pensamento feminista: Diálogos e esclarecimentos, organizado por Eunice Macedo, Sofia Marques da Silva, Fátima Salum, Tânia Brabo, Arilda Ines Miranda Ribeiro e Jorge Luís Mazzeo Mariano, 183-198. Porto: Livpsic.

Cortez, Mirian Béccheri, e Lídio de Souza. 2008. «Mulheres (in)subordinadas: o empoderamento feminino e suas repercussões nas ocorrências de violência conjugal.» Psicologia: Teoria e Pesquisa, 171-180. DOI: https://doi.org/10.1590/S0102-37722008000200006

Crockett, Cailin, Bonnie Brandl, e Firoza Chic Dabby. 2015. «Survivors in the Margins: The Invisibility of Violence Against Older Women.» Journal of Elder Abuse E Neglect, 291302. DOI: https://doi.org/10.1080/08946566.2015.1090361

Damaceno, Daniela G., Miriam F. Sanches Alarcon, Viviane B. Yoneda Sponchiado, Mara Q. Chirelli, Maria J. Sanches Marin, e Joyce F. S. A. Ghezzi. 2019. «Denunciando as agressões: o protagonismo de mulheres idosas vítimas de violência.» In Atas do $8 .^{\circ}$ Congresso Ibero-Americano em Investigação Qualitativa, vol. 2, organizado por A. P. Costa, C. Pinheiro, E. Synthia, J. Ribeiro, H. Presado, C. Baixinho, 1156-1165. Aveiro: Ludomedia. Disponível em https://proceedings.ciaiq.org/index.php/CIAIQ2019/article/ view $/ 2250$ 
Duarte, Maiara Cardoso, Rosa Maria Godoy Serpa da Fonseca, Vânia de Souza, e Érica Dumont Pena. 2015. "Gênero e violência contra a mulher na literatura de enfermagem: uma revisão.» Revista Brasileira de Enfermagem, 325-332. DOI: https://doi. org/10.1590/0034-7167.2015680220i

Freire, Paulo. 1997. Pedagogia da Esperança: um reencontro com a pedagogia do oprimido. São Paulo: Paz e Terra.

Gadotti, Moacir. 1990. «A dialética: concepção e método.» Em Concepção Dialética da Educação, 15-38. São Paulo: Cortez/Autores Associados.

Grose, Rose Grace, e Shelly Grabe. 2014. «The Explanatory Role of Relationship Power and Control in Domestic Violence Against Women in Nicaragua: A Feminist Psychology Analysis.» Violence Against Women, 972-993. DOI: https://doi.org/10.1177/107780121 4546231

IPEA e FBSP - Instituto de Pesquisa Econômica Aplicada e Fórum Brasileiro de Segurança Pública (orgs.). 2019. Atlas da violência. Brasília, Rio de Janeiro, São Paulo: IPEA e FBSP. Disponível em https://www.ipea.gov.br/portal/index.php?option=com_content\&view $=$ article\&id $=34784 \&$ Itemid $=432$

Leite, Maísa Tavares de Souza, Maria Fernanda Santos Figueiredo, Orlene Veloso Dias, Maria Aparecida Vieira, Luís Paulo Souza e Souza, e Danilo Cangussu Mendes. 2014. «Reports of violence against women in different life cycles.» Revista Latino-Americana de Enfermagem, 85-92. DOI: https://doi.org/10.1590/0104-1169.3186.2388

Macedo, Eunice. 2015. «Violência e Violências sobre as mulheres: auscultando lugares para uma democracia «outra» mais autêntica.» Em Mulheres, gênero e violência, por Tânia Suely Antonelli Marcelino Brabo, 15-36. Marília: Cultura Acadêmica.

Mascarenhas, Márcio D. M., Raniela B. Sinimbu, Marta M. A. da Silva, Mércia G. O. de Carvalho, Morgana R. dos Santos, e Mariana G. Freitas. 2016. «Caracterização das vítimas de violência doméstica, sexual e/ou outras violências no Brasil - 2014.» Revista Saúde em Foco 1 (1). Disponível em https://www.smsrio.org/revista/index.php/revsf/article/view/199 [Consultado em 2 de março de 2019].

O’Brien, Marita, Emer Begley, Janet C. Anand, Campbell Killic, Brian Taylor, Evelyn Doyle, Mary McCarthy, Sam McCrossan, e Evelyn Moran. 2011. A Total Indifference to our Dignity: Older People's Understandings of Elder Abuse. Dublin: Age Action.

Ockerent, Christine. 2011. O Livro Negro da Condição das Mulheres. Rio de Janeiro: Difel.

Paraíba, Patrícia Maria Ferreira, e Maria Carmelita Maia e Silva. 2015. «Perfil da violência contra a pessoa idosa na cidade do Recife-PE.» Revista Brasileira de Geriatria e Gerontologia 18 (2): 295-306. DOI: https://doi.org/10.1590/1809-9823.2015.14047

Riutort, Monica, e Sandra Rupnarain. 2017. «In the quest for Equity: Violence against women and conscientization though dialogue from a paternalistic to a symbolic relation with government.» Em Ecos de Freire e o pensamento feminista: Diálogos e esclarecimentos, organizado por Eunice Macedo, Sofia Marques da Silva, Fátima Salum, Tânia Brabo, Arilda Ines Miranda Ribeiro e Jorge Luís Mazzeo Mariano, 229-239. Porto: Livpsic.

SEADE - Sistema Estadual de Análise de Dados. 2019. Perfil dos Municípios paulistas. São Paulo: SEADE. Disponível em http://produtos.seade.gov.br/produtos/projpop/ [Consultado em 10 de novembro de 2019].

Souto, Rafaella Q., Miriam A. B. Merighi, Sepali Guruge, e Maria C. P. de Jesus. 2015. «Older Brazilian women's experience of psychological domestic violence: A social phenomenological study.» International Journal for Equity in Health, 1-9. DOI: https://doi. org /10.1186/s12939-015-0173-z 
Strauss, Anselm, e Juliet Corbin. 2008. Pesquisa Qualitativa: técnicas e procedimentos para o desenvolvimento de teoria fundamentada. 2. Tradução: Luciane de Oliveira da Rocha. Porto Alegre: Artmed.

Tran, Thach Duc, Hau Nguyen, e Jane Fisher. 2016. «Attitudes towards intimate partner violence against women among women and men in 39 low- and middle-income countries.» PLOS ONE 11 (11): e0167438. DOI: https://doi.org/10.1371/journal.pone.0167438

Daniela Garcia Damaceno. Graduada em enfermagem, Mestre em Saúde e envelhecimento pela Faculdade de Medicina de Marília. Doutoranda em enfermagem pela Faculdade de Medicina de Botucatu da Universidade Estadual Paulista «Júlio de Mesquita». Especialista em Saúde da Família e Comunidade pela Faculdade de Medicina de Marília. Docente da Faculdade de Enfermagem da Universidade do Oeste Paulista (UNOESTE).

Endereço eletrônico: daniela.garciasw@gmail.com

Miriam Fernanda Sanches Alarcon. Graduada em enfermagem, Mestre em Ensino em Saúde pela Faculdade de Medicina de Marília. Doutoranda em enfermagem pela Faculdade de Medicina de Botucatu da Universidade Estadual Paulista «Júlio de Mesquita». Especialista em Urgência e Emergência. Atualmente Professor Assistente $C$ da disciplina de Práticas clínicas em alta complexidade da Universidade Estadual do Norte do Paraná (UENP).

Endereço eletrônico: miriam@uenp.edu.br

Viviane Boacnin Yoneda Sponchiado. Bacharel em Direito pela Universidade Estadual do Norte do Paraná (UENP). Mestre em Teoria do Direito e do Estado pelo Centro Universitário Eurípides de Marília (UNIVEM). Delegada da Delegacia de Defesa da Mulher na Central de Polícia Judiciária da Polícia Civil do Estado de São Paulo. Endereço eletrônico: puffy_yoneda@hotmail.com

Mara Quaglio Chirelli. Graduada em Enfermagem, Mestre em Saúde Pública e Doutora em Enfermagem pela Universidade de São Paulo de Ribeirão Preto. Pós-Doutorado em Educação pela Faculdade de Educação da Universidade Estadual de Campinas. Especialista em ativação de Processo de Mudanças na formação em Saúde. Docente do Curso de Enfermagem, do Mestrado Profissional Ensino na Saúde e do Mestrado Acadêmico Saúde e Envelhecimento da Faculdade de Medicina de Marília. Endereço eletrônico: marachirelli@gmail.com

Maria José Sanches Marin. Graduada em Enfermagem, Mestre e Doutora em Enfermagem Fundamental pela Universidade de São Paulo de Ribeirão Preto. Pós-Doutorado em Ciências da Saúde pela Escola Paulista de Medicina. Especialista em ativação de Processo de Mudanças na formação em Saúde. Docente do Curso de Enfermagem, do Mestrado Profissional Ensino na Saúde, do Mestrado Acadêmico Saúde e Envelhecimento da Faculdade de Medicina de Marília e do Mestrado e Doutorado em Enfermagem pela Faculdade de Medicina de Botucatu - Universidade Estadual Paulista. Endereço eletrônico: marnadia@terra.com.br 
Joyce Fernanda Soares Albino Ghezzi. Graduada em enfermagem, Mestre em Ensino em Saúde pela Faculdade de Medicina de Marília. Doutoranda em enfermagem pela Faculdade de Medicina de Botucatu da Universidade Estadual Paulista «Júlio de Mesquita». Pós Graduada em Gestão Estratégica de Pessoas, em Atenção Especializada e Integral às Urgências e em Formação Didática Pedagógica em Enfermagem. Enfermeira Assistencial da Unidade de Terapia Intensiva do Hospital de Clínicas de Marília.

Endereço eletrônico: jo.albino1988@gmail.com

Artigo recebido a 02 de fevereiro e aceite para publicação a 12 de junho de 2020. 